\title{
SELECTIVE W FOR COATING AND RELEASING MEMS DEVICES
}

S. S. MANI*, J. G. FLEMING, J. J. SNIEGOWSKI, M. P. de BOER, L. W. IRWIN, J. A. WALRAVEN, D. M. TANNER, and D. A. La VAN ssmani@sandia.gov

\section{ABSTRACT}

Two major problems associated with Si-based MEMS (MicroElectroMechanical Systems) devices are stiction and wear. Surface modifications are needed to reduce both adhesion and friction in micromechanical structures to solve these problems. In this paper, we will present a CVD (Chemical Vapor Deposition) process that selectively coats MEMS devices with tungsten and significantly enhances device durability. Tungsten CVD is used in the integrated-circuit industry, which makes this approach manufacturable. This selective deposition process results in a very conformal coating and can potentially address both stiction and wear problems confronting MEMS processing. The selective deposition of tungsten is accomplished through the silicon reduction of $\mathrm{WF}_{6}$. The self-limiting nature of this selective $\mathrm{W}$ deposition process ensures the consistency necessary for process control. The tungsten is deposited after the removal of the sacrificial oxides to minimize stress and process integration problems. Tungsten coating adheres well and is hard and conducting, requirements for device performance.

Furthermore, since the deposited tungsten infiltrates under adhered silicon parts and the volume of W deposited is less than the amount of Si consumed, it appears to be possible to release stuck parts that are contacted over small areas such as dimples. The wear resistance of selectively coated W parts has been shown to be significantly improved on microengine test structures.

\section{INTRODUCTION}

Surface micromachined devices are currently fabricated from polycrystalline silicon, which is used by the silicon microelectronics industry as a gate electrode and local interconnect [1]. Parts fabricated from polysilicon, a material originally developed for its electronic properties, have been demonstrated to be mechanically robust [2]. However, wear has been identified as a significant failure mechanism for devices with load bearing surfaces [3-5].

Some approaches to the problem of wear include the introduction of a low friction polymeric coating, for example by PECVD (Teflon) or introduction of self assembled monolayer or through wet chemical routes after the release process $[6,7]$. In these approaches the deposited layer itself is not hard and wear is diminished by the reduction in the coefficient of friction. The long-term behavior of these very thin layers of polymeric materials is unclear. A fundamentally different approach to the wear problem is to substitute the polysilicon with intrinsically hard materials such as diamond or silicon carbide. However, this runs counter to the great enabling strength of surface micromachining, leveraging of IC processing technology and tool sets. An even bigger drawback to this approach involves process integration. Most devices with contacting layers consist of a minimum of three mechanical levels fabricated using a complicated combination of deposition, photolithographic, etch, and planarization processes. The introduction of completely new materials and processing technologies into these complex process flows may be difficult. Therefore, development of better surface passivation and tribological coatings using standard IC processing tool set is of great importance for the successful widespread introduction of MEMS sensors and actuators with contacting surfaces. In this paper we demonstrate that coating with 


\section{DISCLAIMER}

This report was prepared as an account of work sponsored by an agency of the United States Government. Neither the United States Government nor any agency thereof, nor any of their employees, make any warranty, express or implied, or assumes any legal liability or responsibility for the accuracy, completeness, or usefuiness of any information, apparatus, product, or process disclosed, or represents that its use would not infringe privately owned rights. Reference herein to any specific commercial product, process, or service by trade name, trademark, manufacturer, or otherwise does not necessarily constitute or imply its endorsement, recommendation, or favoring by the United States Government or any agency thereof. The views and opinions of authors expressed herein do not necessarily state or reflect those of the United States Government or any agency thereof. 


\section{DISCLAIMER}

\section{Portions of this document may be illegible in electronic image products. Images are produced from the best available original document.}


selectively deposited, self-limiting, tungsten coating can dramatically improving the wear characteristics of microengines.

The selective deposition of tungsten through the silicon reduction of $\mathrm{WF}_{6}$ was studied in detail in the late 1980's but never gained acceptance by the IC industry [8-13]. However, blanket tungsten CVD, using silane or hydrogen reduction is commonly used in the integrated-circuit industry, and this same tool set can be applied to the selective silicon reduction process outlined here. The selective deposition of tungsten is accomplished through silicon reduction of $\mathrm{WF}_{6}$, which results in a self-limiting reaction $[11,12]$. The self-limiting nature of this deposition process ensures the consistency necessary for process control and results in a very conformal coating. The ability to selectively deposit $\mathrm{W}$ after the removal of the sacrificial oxide and the low temperature of the deposition $\left(<450^{\circ} \mathrm{C}\right)$ eases process integration. Furthermore, since the deposited tungsten infiltrates under adhered silicon parts and the volume of $W$ deposited is less than the amount of Si consumed, it appears to be possible to release adhered parts that are contacted over small areas such as dimples.

Tungsten has a number of attractive properties as a wear resistant coating. Endurance of the W coating is important, especially in applications where wear may occur due to rubbing or contacting surfaces. Unlike polymeric coatings, which only serve to reduce the coefficient of friction, $W$ is hard. Also unlike the polymers, $W$ is entirely compatible with the temperatures typically associated with packaging and is ultra high vacuum compatible.

\section{EXPERIMENT}

The chemical reactions for selective $\mathrm{W}$ deposition using chemical vapor deposition are given below:

$$
\begin{aligned}
& 2 W_{6}+3 \mathrm{Si} \longrightarrow 2 W+3 \mathrm{SiF}_{4} \uparrow \quad \text { (1) and } \\
& W F_{6}+3 \mathrm{Si} \longrightarrow W+3 \mathrm{SiF}_{2} \uparrow
\end{aligned}
$$

When $\mathrm{WF}_{6}$ encounters heated silicon, a reaction occurs in which $\mathrm{SiF}_{4}$ or $\mathrm{SiF}_{2}$ gas is formed and $\mathrm{W}$ is deposited on the silicon surface. Depending on the reaction temperature one reaction or the other dominates $[10,13]$. Once a continuous film of $W$ is formed (after $\sim 200 \AA$ on our structural polysilicon) the $\mathrm{WF}_{6}$ is shielded from the $\mathrm{Si}$ and the reaction slows or stops. This process is completely selective since the reaction does not occur on silicon dioxide or silicon nitride $[14,15]$.

The selective $W$ deposited on polysilicon surfaces is extremely conformal as shown in a SEM micrograph in Figure 1. After cleaving, the polysilicon has been etched using $\mathrm{HNO}_{3}: \mathrm{HF}$ to delineate the extremely thin $\mathrm{W}$ coating around the polysilicon, a cantilever in this case. The $W$ on the

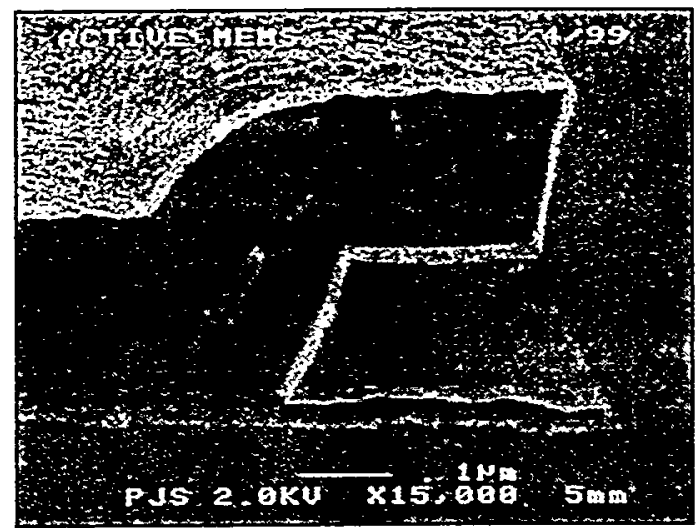

Figure 1. A scanning electron micrograph showing a thin $\sim 100 \AA$ layer of silicon reduced $\mathrm{W}$ conformal around all sides of a section of structural polysilicon. The silicon has been recessed using a $\mathrm{HF} / \mathrm{HNO}_{3}$ mixture in order to delineate the $\mathrm{W}$. top surface is continuous even after this aggressive etch, demonstrating the absence of pin holes which would have been enhanced during etching.

During the displacement reduction reaction of $\mathrm{Si}$ by $\mathrm{WF}_{6}$ discussed earlier, the amount of $\mathrm{Si}$ thickness consumed is about twice the thickness of tungsten formed. This inherent difference in the deposited film thickness and the reacted film thickness results in $\mathrm{W}$ depositing in very narrow spaces making this process desirable for MEMS devices. Figures $2 \mathrm{a}$ and $2 \mathrm{~b}$ show 
undercutting in initially adhered Si members. The SEM image shows the backside of a cantilever beam where $W$ has deposited. The structure was pulled using carbon-tape to image the backside. It appears that $\mathrm{W}$ has penetrated between layers of $\mathrm{Si}$, which were initially adhered. If the contact area is kept small this may be a way to address the stiction problem. This is also important in that it is a mechanism for the coating of portions of parts that are unavoidably in local contact at the end of the drying process. Standard deposition processes either do not coat these contacting regions or can act to further glue them together.

\section{WEAR RESISTANCE OF TUNGSTEN-COATED MICROENGINES}

MEMS devices were selectively coated with $\mathrm{W}$ using the selective silicon reduction process outlined above [15]. The microengine

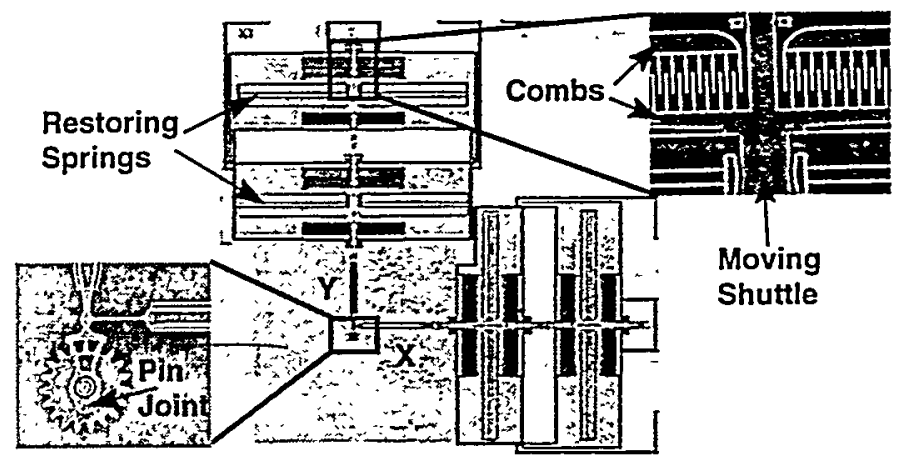

Figure 3. Sandia microengine with expanded views of the comb drive (top right) and the rotating gear (bottom left).

5].

One of the many issues associated with assessing the reliability of microengines is the method used to operate them. Ideal equations (model-based), based on Newtonian physics, were derived to optimize the electrical signals [16]. In the typical optimization procedure, parameters were measured [17] which were then input into the equations. These equations are NOT simple sine waves, and it has been demonstrated that operation by square waves produced early failures [18].

To make a clean comparison to the polysilicon microengine, we decided to use the same drive parameters and frequency $(1720 \mathrm{~Hz})$ used in an earlier test. All of the earlier tests were stressed 
with a large longitudinal force to accelerate the time to failure. The same was done with the tungsten-coated devices.

In our earlier tests without the coating, we observed a median time to failure of $4 \times 10^{5}$ accumulated cycles using a sample size of more than 20 microengines. This was performed in a controlled humidity environment of $39 \%$ RH. Using the same drivesignal parameters, but in ambient laboratory conditions (30-50\%RH), we observed a dramatic increase in the time to failure for $W$ coated parts. We saw no failures in 30 samples tested to 2 million cycles. Two microengines ran normally for $1,035,000,000$ and $379,000,000$ cycles
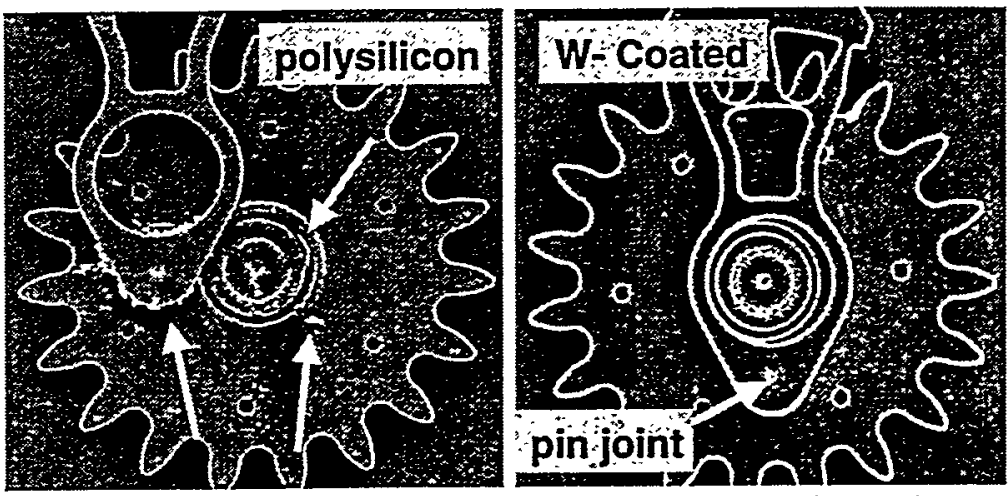

Figure 4. This SEM image shows the wear debris on the face of the polysilicon gear after 1 million cycles. Arrows indicate the location of wear debris. In contrast, the tungsten-coated gear has no indication of wear after 1 billion stress cycles. The gear diameter is 76 microns. respectively after which the test was stopped. One microengine was stressed using square waves and ran for $258,000,000$ cycles without failure.

As shown in Figure 4, there is no apparent wear debris of the $\mathrm{W}$ coated devices. The
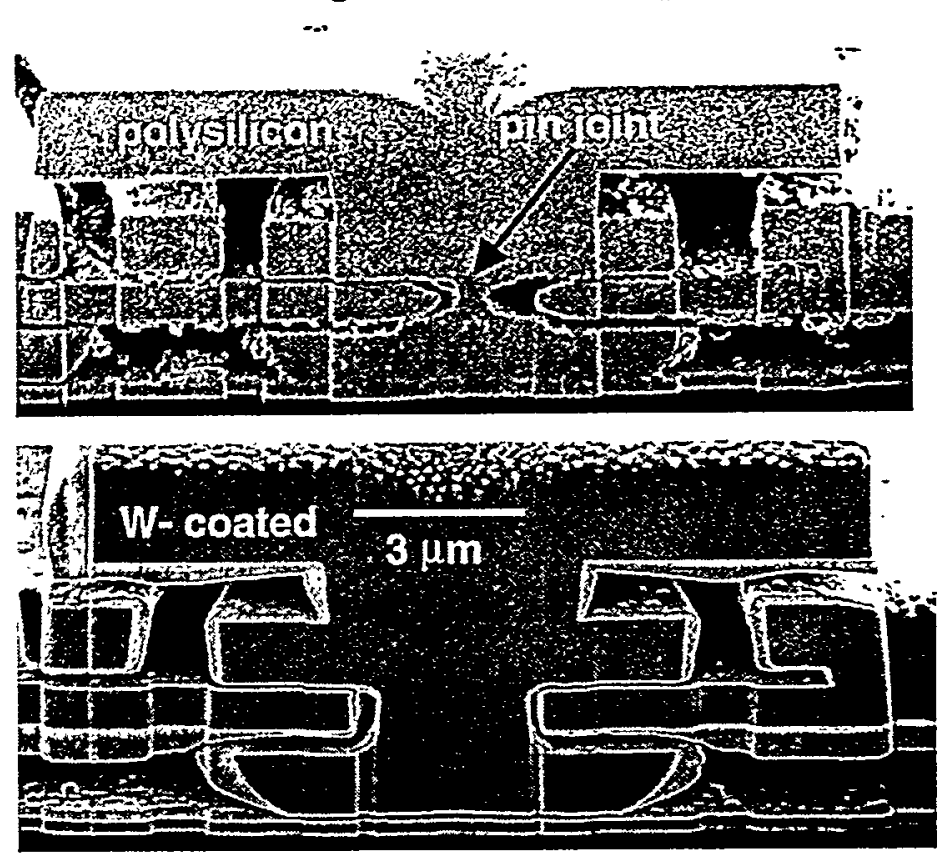

Figure 5. The top image shows a polysilicon gear's pin joint after 607,000 accumulated cycles. Note the wear debris and the narrowing of the pin joint from its nominal 3 micron diameter. In comparison, the tungsten-coated pin joint shows no wear debris after 1 billion accumulated cycles. The overhanging and fillet features are FIB artifacts. polysilicon gear on the left failed after 1 million cycles with wear debris forming inside the hub and near the pin joint region. In comparison, on the right is a tungsten-coated microengine gear with no signs of wear debris after a billion cycles.

Further confirmation of excellent wear resistance is shown in Figure 5 by focussed ion beam (FIB) cross sections of the pin joint region. The pin joint has a diameter of 3 microns. The polysilicon pin joint failed at 607,000 cycles and shows excessive wear with a significant narrowing of the diameter. Wear debris was present on all the rubbing surfaces. In contrast, the tungsten-coated pin joint shows no wear or wear debris anywhere near the rubbing surfaces.

Miniature tensile samples have been tested to investigate the affect of tungsten coating on the strength of polysilicon. Each sample has a freely moving pivot and a pull-ring; the gage crossection is $1.8 \mu \mathrm{m}$ wide by $2.5 \mu \mathrm{m}$ 
thick and varies in length from 15 to $1000 \mu \mathrm{m}$. The pull-ring is engaged by a $35 \mu \mathrm{m}$ diameter flat tipped diamond using a nanoindenter. The normal force, lateral force and displacement are recorded. The normal force is maintained throughout the test to prevent the conical shaped diamond from being pushed upwards by the pull-ring engagement reaction. Once engaged, the tip continues to move laterally, which loads the thin polysilicon ligament in tension. Figure 6 shows two samples: the lower one has been tested.

Ninety-eight $\mathrm{SCCO}_{2}$ released and 50 tungsten coated samples were tested. There was a significant difference between the two groups. The mean and $\mathrm{SD}$ for the $\mathrm{SCCO}_{2}$ released samples is $4.27 \pm 0.61 \mathrm{GPa}$ while the tungsten coated samples decreased to $2.77 \pm 0.60 \mathrm{GPa}$ shown in Figure 7. The minimum values for each group dropped more precipitously, dropping from $2.91 \mathrm{GPa}$ to $1.44 \mathrm{GPa}$. No difference could be established between the strengths of samples of different lengths within each group. While the strength has been lowered for tungsten coated polysilicon, it remains sufficiently high for most MEMS applications. More details about this technique are in reference [19]. TEM micrographs show particles at the tungsten-silicon interface, which may result in a stress concentration lowering the stress for static failure. Further work in understanding the W-Si interface is in progress.

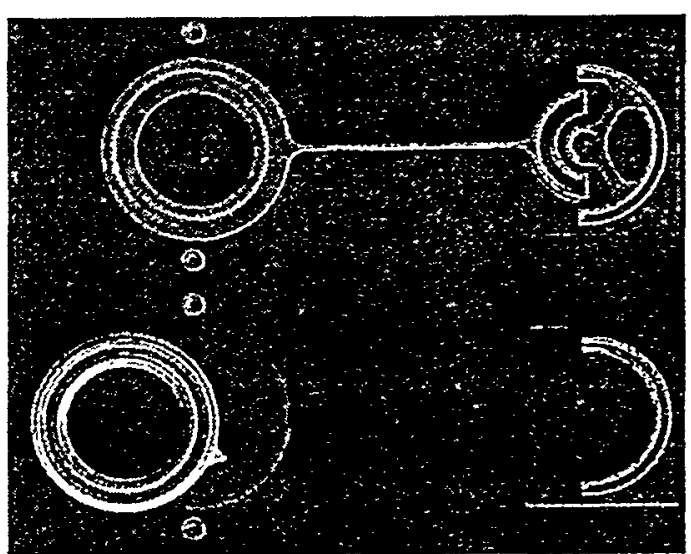

Figure 6. Two polysilicon tensile samples. The gage length for both samples is $90 \mu \mathrm{m}$. The lower sample has been tested; the energy released at fracture broke the pivot.

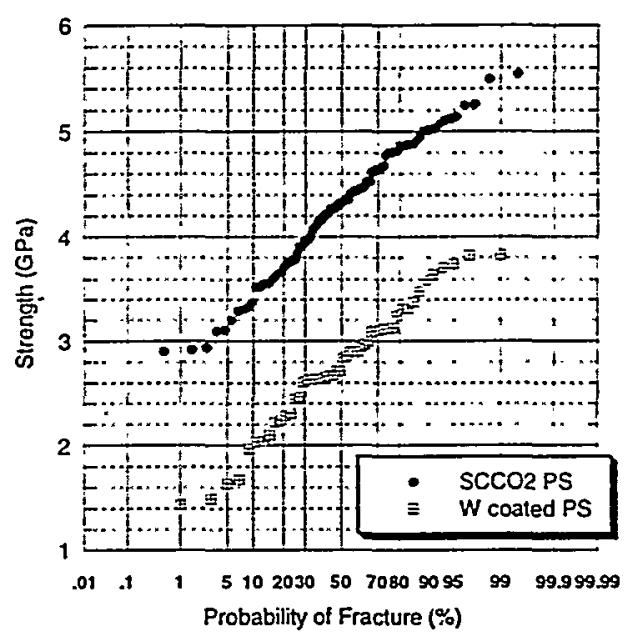

Figure 7. Cumulative probability of failure for polysilicon samples released using supercritical $\mathrm{CO}_{2}$ and Tungsten coated.

\section{CONCLUSIONS}

Selective tungsten coating using chemical vapor deposition has been used to deposit a thin, uniform, conformal coating to improve wear resistance. This $\mathrm{W}$ coating shows dramatic improvements in wear characteristics. Microengines coated with selective W show longer lifetimes than polysilicon microengines. The mean time to failure observed in polysilicon microengines was $4 \times 10^{5}$ using 20 microengines. In comparison, in the tungsten coated microengines no failure was observed in 30 microengines tested to 2 million cycles.

\section{ACKNOWLEDGEMENTS}

The United States Department of Energy under contract DE-AC04-94AL85000 supported this work. Sandia is a multiprogram laboratory operated by Sandia Corporation, a Lockheed Martin Company, for the United States Department of Energy. The authors acknowledge the 
staff in MDL for their efforts and Pat Shea for all the SEM work and Alex Pimental for the FIB cuts.

\section{REFERENCES}

1. R. T. Howe and R. S. Muller, J. Electrochem Soc: Solid State Science \& Technology, 103(6) p. 1420 (1983).

2. E. J. Garcia and J. J. Sniegowski, Sensors and Actuators A, 48, p. 203 (1995).

3. S. L. Miller, J. J. Sniegowski, G. LaVigne, and P. J. McWhorter in Proceedings of SPIE Smart Electronics and MEMS 2722, p. 197 (1996).

4. Danelle M. Tanner, W. M. Miller, W. P. Eaton, L. W. Irwin, K. A. Peterson, M. T. Dugger, D. C. Senft, N. F. Smith, P. Tangyunyong, and S. L. Miller in 1998 IEEE International Reliability Physics Proceedings, p. 26 (1998).

5. Danelle M. Tanner, Jeremy A. Walraven, Lloyd W. Irwin, Michael T. Dugger, Norman F. Smith, William M. Miller, and Samuel L. Miller in Proc. Of IEEE International Reliability Physics Symposium, p. 189 (1999).

6. K. Deng, R. J. Collins, M. Mehrengany and C. N. Sukenik, J. Elctrochem. Soc., 142(4), p. 1278 (1995).

7. U. Srinivasan, M. R. Houston, R. T. Howe and R. Maboudian, J. Micromech. Sys., 7(2), p. 252 (1998).

8. D. R. Bradbury, J. E. Turner, K. Nauka and K. Y. Chiu, IEDM, p. 273, (1991).

9. M. Sekine, Y. Kakuhara, K. Yamazaki and Y. Murao, MRS Advanced Metallization ULSI Applications, p. 255, (1991).

10. M. L. Yu, B. N. Eldridge, and R. V. Joshi, in Deposition and Growth: Limits for Microelectronics, edited by G. W. Rubloff (AIP Conf. Proc. 167, New York 1988), p. 202.

11. E. K. Broadbent and C. L. Ramiller, J Elctrochem. Soc.: Solid-State Science and Techonolgy, 131(6), p. 1427 (1984).

12. M. L Green and R. A. Levy, J Elctrochem. Soc.: Solid-State Science and Techonolgy, 132(5), p. 1243 (1985).

13. M. L. Yu, B. N. Eldridge, and R. V. Joshi, in Tungsten and Other Refractory Metals for VLSI Applications III, edited by V. A. Wells (MRS Proc. Pittsburgh, PA), 1988, p. 75.

14. A. Kepten, A. Reisman, M. Ray, P. L. SMith, D. Temple, and F. Tapp, J. Electrochem. Soc, 139(8), p. 2331 (1992).

15. S. S. Mani, J. G Fleming, and J. J. Sniegowski in Proceedings of SPIE, Micromachining and Microfabrication Process Technology V, 3874, p.150 (1999).

16. S. L. Miller, J. J. Sniegowski, G. LaVigne, and P. J. McWhorter in Proceedings of SPIE Micromachined Devices and Components II, 2882, p. 182 (1996).

17. Norman F. Smith, William P. Eaton, Danelle M. Tanner, and James J. Allen in ȘPIE Proceedings, 3880, p. 156 (1999).

18. S. L. Miller, M. S. Rodgers, G. LaVigne, J. J. Sniegowski, P. Clews, D. M. Tanner, K. A. Peterson in Proc. Of IEEE International Reliability Physics Symposium, p. 17 (1998).

19. LaVan, D. A. and T. E. Buchheit in Symposium MM Materials Science of MicroElectroMechanical System (MEMS) Devices II, Proceedings of the 1999 MRS Fall Meeting Dec 1-3 1999 Boston. 